\title{
Educación intercultural, diversidad y creatividad en el aula a través del teatro: los títeres
}

\author{
Miquel A. OltRa AlBiaCH \\ Universitat de València \\ Departament de Didàctica de la Llengua i la Literatura \\ miquel.oltra@uv.es
}

Recibido: 3 de diciembre de 2014

Aceptado: 1 de abril de 2015

\section{RESUMEN}

La educación intercultural y el tratamiento de la diversidad en la escuela son sin duda algunos de los aspectos de la educación sobre los que más se ha escrito en las últimas décadas. Con el presente trabajo pretendemos hacer un recorrido por los planteamientos más actuales en la educación intercultural, así como la profundización en la idea de creatividad y en el trabajo colaborativo como formas eficaces de afrontar el reto que nos plantea la diferencia. Finalmente, propondremos literatura, concretamente el teatro de títeres, como herramienta didáctica óptima para el trabajo intercultural en todos los niveles educativos, partiendo de la valoración positiva de la diversidad en sus múltiples significados.

Palabras clave: creatividad, diversidad, educación intercultural, literatura, teatro, títeres

\section{Intercultural education, diversity and creativity in the classroom through the theater: the puppets}

\begin{abstract}
Intercultural education and treatment of diversity in the school are certainly some aspects of education on which more has been written in recent decades. With this work we intend to take a tour of the current approaches in intercultural education and deepening the idea of creativity and collaborative work as effective ways to meet the challenge posed by the difference. Finally, we propose literature, specifically puppetry as an optimal teaching tool for intercultural work in all educational levels, from the appreciation of diversity in its multiple meanings.
\end{abstract}

Key words: creativity, diversity, multicultural education, literature, theatre, puppets

\section{L'éducation interculturelle, la diversité et la créativité dans la classe}

\section{RÉSUMÉ}

\section{à travers le théâtre: les marionnettes}

L'éducation interculturelle et le traitement de la diversité à l'école sont certainement des aspects de l'éducation sur lesquels plus ont été écrit au cours des dernières décennies. Avec ce travail, nous voulons faire un tour des approches actuelles en matière d'éducation interculturelle et d'approfondir l'idée de la créativité et le travail collaboratif comme des moyens 
efficaces pour relever le défi que représente la différence. Enfin, nous proposons la littérature, en particulier la marionnette comme un instrument optimal d'enseignement pour le travail interculturel de tous les niveaux educatifs, à partir de l'appréciation de la diversité dans ses multiples significations.

Mots-clés: créativité, diversité, éducation interculturelle, littérature, théâtre, marionnettes

SUMARIO: 1. Introducción; 2. Interculturalidad, diversidad y educación; 3. El tratamiento de la diversidad en la escuela; 4. La creatividad del alumnado como punto de partida; 5. Diversidad, literatura y títeres; 6. Conclusiones; 7. Bibliografía.

\section{INTRODUCCIÓN}

La educación intercultural y la atención a la diversidad son dos de los aspectos de la educación que más relieve han adquirido en las últimas décadas. Hay muchos ámbitos de diversidad susceptibles de ser tratados al aula, con la tolerancia y la aceptación de la diferencia como fundamento. Sin embargo, la educación intercultural está llamada a dar un paso más allá: desde la base irrenunciable que constituye el respeto y la tolerancia a todo el mundo, nos planteamos llegar a la valoración positiva de la diversidad como una riqueza que hay que entender y asumir. No se trata de acciones puntuales, ni de proyectos destinados a determinados momentos y para determinados grupos en situación desfavorable: hablamos de un proyecto global para todo el alumnado. En definitiva, se trata de construir una cultura de la diversidad, lo cual tiene repercusiones en los currículos escolares y también en la formación del profesorado:

Consideramos que es preciso educar generaciones que no le tengan miedo a las diferencias. Educar seres abiertos y curiosos a otras personas y situaciones. Y eso sólo será posible si el profesorado desarrolla la capacidad de atender a la diversidad de los aprendices. Esto no debe considerarse como un esfuerzo suplementario o un procedimiento excepcional que hay que organizar en determinados momentos y para determinados alumnos y alumnas. Muy al contrario, esta capacidad significa que lo normal es la diversidad, lo normal es la heterogeneidad (Alegre, 2010: 34).

No hay ningún duda de que estamos ante unos de los grandes retos de la educación, que afecta no solo a las relaciones entre la población originaria de un determinado lugar y el colectivo inmigrante, sino también a la manera en que las personas -todas las personas- construimos la propia identidad y, sobre todo, a la necesidad de superar determinadas maneras tradicionales de pensar y de actuar en relación a la concepción de la ciudadanía.

Por su parte, la literatura es siempre un lugar de encuentro (Prawer, 1998: 32), en primer lugar entre el autor y el receptor, muchas veces separados físicamente por factores temporales, espaciales, lingüísticos y culturales. En este sentido, tal como nos recuerda Josep Ballester (2007: 98): “en la lengua y la literatura se encuentran 
depositados y vivos los esquemas de valores y de visión del mundo que presentan las diferentes comunidades humanas, como también determinadas pautas de conducta y sabiduría popular gestadas a lo largo de generaciones". Es justamente en esta capacidad de la literatura de poner frente a frente y en situación de diálogo a las diversas culturas humanas donde centraremos nuestra propuesta didáctica.

\section{INTERCULTURALIDAD, DIVERSIDAD Y EDUCACIÓN}

A la hora de definir la educación intercultural, la mayoría de autores coinciden en una serie de características que Auxiliadora Sales resume de la siguiente manera:

Partimos de la idea que la Educación Intercultural es un modelo educativo que propicia el enriquecimiento cultural de la ciudadanía, partiendo del reconocimiento y el respeto a la diversidad, mediante el intercambio y el diálogo, en la participación activa y crítica para el desarrollo de una sociedad democrática basada en la igualdad, la justicia y la solidaridad (Sales, 2003: 9).

Teresa Aguado pone de relieve que la pedagogía intercultural nace en un contexto sociopolítico que evoluciona desde las llamadas posturas asimilacionistas en el tratamiento de las diferencias culturales hacia otras perspectivas en los que estas diferencias se abordan desde la referencia a los valores democráticos de equidad y participación social. Esta autora hace notar que el término educación intercultural, generalizado en el contexto europeo, se refiere a una tendencia reformadora en la práctica educativa, amplia y variada en cuanto a las metas, con la que se trata de responder a la diversidad provocada por la convivencia de diferentes grupos culturales en el seno de una sociedad, superando modelos antiguos e ineficaces. La educación intercultural implica interacción, intercambio, ruptura del aislamiento, reciprocidad y solidaridad objetiva entre las culturas, y también reconocimiento y aceptación de los valores y los modos de vida de los otros (Aguado, 2003: 33).

En la misma línea, Olga María Alegre (2010: 46) resalta que la base de una educación inclusiva es valorar las normas, la cultura y las formas de convivencia del alumnado que pertenece a minorías étnicas o culturales. La educación inclusiva implicaría, como elemento básico, el aprendizaje conjunto con independencia de las condiciones personales, sociales y culturales de los aprendices, incluyendo las personas con discapacidad. Se trata de medidas que atañen al conjunto del alumnado, y no solo a las minorías, porque la interculturalidad tiene que ver con el conjunto de la sociedad y no solo con los colectivos minoritarios (Alegre, 2004: 33). La conciencia de la necesidad de esta educación para el conjunto de los discentes, tal como explica Margarita Bartolomé, está aún por generalizar entre el colectivo docente, que a menudo confunde las medidas compensatorias (sobre todo lingüísticas) de cara al alumnado inmigrante con la educación intercultural: 
La necesidad experimentada como urgencia por el profesorado era conseguir una competencia aceptable de la lengua escolar, por parte del alumnado inmigrante. Todas las otras diferencias culturales y, especialmente, la consideración de que la educación intercultural afecta a todo el alumnado y no únicamente a los que consideramos "diferentes", quedaban relegadas a un segundo plano o no aparecían con claridad en la conciencia del profesorado (Bartolomé, 2008: 14).

Asimismo, por lo que respecta a la diversidad cultural, se trata de incorporar aspectos o elementos lingüísticos, sociales, culturales, etc., de las minorías en la docencia, como caracteres que sirven para que estas personas se sientan identificadas y valoradas positivamente, además de servir de enriquecimiento personal para el resto. Desde aquí pasamos a la idea de interculturalidad, que no debemos confundir con la simple aculturación de la parte más débil por el sector mayoritario (Mínguez, 2010: 563); en este sentido, tal como remarcan Ollé y Colomé (2010: 11), respetar la diversidad y trabajar desde ella es transmitir la idea de que cada ser humano es diferente y valioso en sí mismo.

Es obvio que el sentimiento de pertenencia es imprescindible para generar una ciudadanía activa, y es necesario, para llevar a cabo avances en la construcción de una ciudadanía mundial, estudiar en profundidad el sentimiento de identificación con la propia comunidad, y también hay que tener en cuenta la importancia de la identidad colectiva (Marín, 2008: 40-41). Igualmente, hay que recordar que toda persona necesita pertenecer a una comunidad social y cultural que le proporcione un referente cultural; este referente es necesario para otorgar un orden y dotar de sentido la realidad que le rodea. La pertenencia cultural y nacional proporciona un sentimiento de identidad y es en este sentido una fuente de confianza; sin embargo, si llevamos al extremo la defensa de la tradición, de la propia identidad y de la diferencia podríamos llegar a conflictos imposibles de resolver. Por tanto hay que mantener un equilibrio, siempre inestable, entre particular y universal, entre tradición y cambio, etc.

La mundialización debe significar pluralidad y diversidad. El valor de esta diversidad cultural no se plantea como diferenciación, sino como posibilidad de acceder a culturas de grupos diferentes del propio. Así, la afirmación de una identidad inmutable y que adquirimos al nacer no es ya una actitud natural, sino que la identidad pasa a ser un acto de elección entre todo un abanico de posibilidades (Marín, 2008: 43). Por otro lado, el acceso a otras culturas nos permite apreciar la singularidad y también las fortalezas y las limitaciones de la nuestra. Finalmente, ninguna forma de vida puede expresar ella sola toda la gama de las potencialidades humanas.

El gran valor de la diversidad cultural -y que hay que potenciar en los entornos educativos- no es solo la diferencia, sino el hecho de que proporciona oportunidades de comunicación entre formas de vida diversas. Por otro lado, se debe ser consciente de que cabe la posibilidad del conflicto, pero también la capacidad -y este es 
uno de los principales objetivos de la educación intercultural- de resolverlo de manera pacífica y de aprender en el proceso.

Por tanto, es una tarea de la educación el trabajo orientado a que todas las personas puedan asumir sus múltiples pertenencias, para conciliar la necesidad de identidad propia con la apertura a lo diferente: quien sea capaz de asumir de manera plena su diversidad podrá ser enlace entre las diversas culturas y comunidades de su entorno, una función imprescindible y fundamental en las sociedades actuales.

\section{EL TRATAMIENTO DE LA DIVERSIDAD EN LA ESCUELA}

Es importante resaltar el diálogo necesario entre culturas como instrumento de conocimiento y de enriquecimiento mutuo más allá de las fronteras geográficas o de cualquier otro tipo, ya que hablamos de la convivencia entre culturas que comparten un mismo espacio físico a partir del respeto a los derechos fundamentales de los seres humanos. Igualmente, hay que resaltar la contribución de las diversas culturas a la creación de un patrimonio común, de un imaginario colectivo compartido por toda la ciudadanía.

Hablamos por tanto de la adquisición de competencias interculturales: habilidades cognitivas, afectivas y prácticas necesarias para moverse con eficacia en un medio intercultural (Aguado, 2003: 141). Se trataría de uno de los principales objetivos de la educación intercultural e implican al alumnado, pero también los docentes, las familias y el resto de personas que constituyen su entorno. Esta competencia intercultural es uno de los elementos que configuran la competencia ciudadana $-\mathrm{y}$ por tanto un elemento insoslayable en la educación para alcanzar esta competencia.

Dentro de las competencias interculturales deberíamos poner especial atención en las actitudes interculturales, en el conocimiento del otro y en las habilidades de interpretación y comparación, por una parte, y en las de aprendizaje e interacción, de otra. Las actitudes interculturales se referirían a la capacidad de apertura mental para aceptar la diferencia cultural y desarrollar la empatía. En cuanto a los conocimientos, se trata de interesarse por los grupos sociales con los que se convive, sus inquietudes, las costumbres, las producciones y como se ven a sí mismos y a los otros en la nueva cultura en que se encuentran insertados. Finalmente, las habilidades de interpretar y comparar tienen que ver con lo que se sabe de la otra cultura, y con la capacidad de relacionarlo, compararlo con la cultura propia e identificar los malentendidos culturales; las habilidades de aprendizaje e interacción estarían relacionadas con la adquisición de conocimientos de otras culturas y con la capacidad de ponerlos en práctica en situaciones reales de comunicación.

La necesidad de desarrollar estrategias y técnicas para la educación en actitudes y valores interculturales ha sido objeto de las reflexiones de especialistas como Rafaela García y Auxiliadora Sales. Para estas autoras es muy importante que el profesorado disponga de herramientas adecuadas para que las actividades de aprendizaje provoquen formas de interacción y de comunicación entre el alumnado que "tengan como consecuencia un acercamiento emotivo basado en el diálogo com- 
prensivo, la escucha respetuosa y la libre expresión de puntos de vista diferentes, pero al mismo tiempo enriquecedores en la forma de comunicarse" (García y Sales, 2003: 47). Se trata sobre todo de una tarea de acercamiento mutuo entre las diversas culturas, y del trabajo al aula de los estereotipos y los prejuicios étnicos, culturales y lingüísticos (Ballester y Mas, 2003: 15).

El desarrollo curricular posibilita toda una serie de planificaciones y aplicaciones por lo que respecta al trabajo intercultural en el contexto concreto del centro escolar y del aula. El elemento clave para esta tarea de adaptación es el Proyecto Educativo de Centro (PEC), que puede pasar a ser instrumento básico para la introducción de una perspectiva intercultural capaz de modular el currículo. Tal como hace notar Auxiliadora Sales, se trata de un currículo que debe ser común, abierto y plural, buscando el equilibrio entre comprensividad y diferencia, la representatividad de la diversidad a los contenidos y estrategias de aprendizaje al aula y la transformación de las escuelas en espacios de creación de proyectos compartidos y de participación democrática inclusiva. Y entre los compromisos que comporta la puesta en práctica de este proyecto, hay que resaltar la sensibilización de la comunidad educativa sobre la diferencia y la necesidad de educar en la diversidad, el compromiso en la eliminación de discriminaciones y la atención educativa a las situaciones de desventaja, la atención prioritaria a las finalidades educativas y a los condicionantes del clima de trabajo de los centro escolar y, finalmente, el planteamiento de una orientación participativa, colaborativa y democrática en las estructuras y la dinámica de gestión del centro, y el establecimiento de una relación próxima entre el centro educativo, las familias y el entorno (Sales, 2005: 9-10). Según palabras de esta autora:

Se trata, en definitiva, de democratizar el currículo teniendo como referencia la diversidad, de manera que todos tengan las mismas oportunidades desde la flexibilidad en la que sea posible la diversificación no discriminatoria. Además, un currículo democrático debe intentar que los conocimientos que se adquieren habiliten para participar activamente en la cultura general; esto tiene dos vertientes: requiere que los individuos confíen en sí mismos, partiendo de su propia cultura, pero también requiere la conexión con una cultura general. El centro educativo puede ejercer esta tarea de mediación y confrontación, permitiendo que todos los colectivos encuentren experiencias con las que se puedan identificar (Sales, 2005: 10).

Aparte de los bloques de contenidos de las diversas materias del currículo, otros materiales idóneos podrían ser textos que aporten propuestas de tratamiento de alguna cultura específica. Estos textos, pese a su especificidad, pueden dar un buen resultado si se utilizan de manera complementaria a otros materiales, tal como destaca Xavier Lluch. Otros posibles recursos serían aquellos materiales relacionados con el trabajo de las actitudes y los valores, y las metodologías como los enfoques cooperativos, de interacción, de diversificación, de simulación, etc. (Lluch, 2003: 
29-32). Otro grupo de materiales permitirían el trabajo intercultural en una perspectiva más global, considerando la implicación de las diversas áreas y atendiendo contenidos de distinta naturaleza (por ejemplo "semanas de", si se utilizan contextualizadamente y de manera integrada con propuestas de trabajo más amplias). Este autor aún considera otras posibilidades en cuanto a materiales curriculares:

Otros materiales plantean la orientación metodológica que deberíamos utilizar para favorecer una construcción del conocimiento que tenga en cuenta la diversidad cultural. Desde esta perspectiva, cualquier tópico del currículo nos facilitaría la oportunidad de poner de relieve perspectivas culturales diferentes en su explicación. Esa es la orientación incipiente de algunas unidades didácticas (Lluch, 2003: 32).

Finalmente, el autor tiene en cuenta otros materiales que, a pesar de no haber sido concebidos como curriculares, pueden rentabilizarse educativamente y ser empleados en el ámbito escolar, como la literatura infantil y juvenil y algunos productos audiovisuales.

\section{LA CREATIVIDAD DEL ALUMNADO COMO PUNTO DE PARTIDA}

La creatividad es sin duda un elemento imprescindible para que exista proceso educativo: más aún, sin ella el ser humano carecería de uno de los elementos que lo configuran como tal. Entendemos la creatividad desde la perspectiva de autores como Menchén (1998, 14-18), es decir, como una necesidad primaria. La ausencia de creatividad produce desmotivación, insatisfacción y aburrimiento. Menchén alerta del peligro de que la opción por la creatividad de los currículos quede en simples intenciones:

Las escuelas nuevas, los movimientos pedagógicos de vanguardia, la escuela activa, de todos los países y también en el nuestro, se han hecho eco de este mensaje y defienden que la creatividad es una aptitud que es necesario desarrollar. Consecuentes con esta afirmación dan cabida, por lo menos en grandes principios, a propuestas y objetivos que harán florecer el talento creativo. Pero sería un grave error dejarlo en mera declaración de intenciones, tan general y generosa como infecunda, si no se lleva a la práctica, con medidas, métodos y materiales adecuados (Menchén, 1998: 15).

Así, el autor reclama sistemas educativos que estimulen e incentiven desde el principio el hecho de mostrar curiosidad, y que organice la enseñanza de tal manera que cada aprendizaje conlleve su recompensa. Ello supone, como es lógico, un cambio en profundidad en unas estructuras educativas generalmente pensadas para que el niño adquiera la "forma correcta" de hacer las cosas, más que interesadas en la alegría de tocar, descubrir, experimentar y crear. El alumno ha de reinventar su realidad y el docente tiene que ofrecerle oportunidades para conseguirlo. 
Desde todos estos supuestos, se plantea un modelo de aprendizaje basado en la estimulación de la creatividad: el modelo IOE (Imaginación, Originalidad, Expresión), que se plantea como un modelo óptimo para cualquier disciplina del área artística, aunque sobretodo se ha desarrollado en las materias de expresión plástica y música (dejando fuera de manera inexplicable actividades como la expresión literaria, la dramatización o el teatro de títeres). La mayor parte de los desarrollos curriculares que se han realizado en los últimos años a partir del modelo IOE continúan con este olvido, que margina claramente cualquier actividad literaria o dramática a pesar de que el modelo es claramente aplicable en estos ámbitos y así está considerado en el modelo teórico.

Consideramos por tanto que sería conveniente trabajar desde este modelo la dramatización en el aula y el teatro (vinculados directamente con el área artística y también con la lingüística y literaria, desde una perspectiva productiva y no meramente de recepción). Tomando como punto de partida una serie de elementos básicos, el modelo IOE propone una taxonomía de objetivos y capacidades creativas en los cuales se conjugan las tres dimensiones que intervienen en el proceso de enseñanza-aprendizaje: las áreas del currículo, las estrategias para el profesorado y las capacidades que es necesario estimular en el aprendiz. En ese punto de partida se articulan la imaginación, la originalidad y la expresión entre sí y con la creatividad.

Este planteamiento, que supone sin duda una nueva concepción del proceso educativo y de los actores que en él participan, implica de manera especial al profesorado, que ha de ser consciente de los bloqueos y las inercias educativas que impiden a los niños ser creativos, y que también ha de revisar determinados hábitos y actitudes adquiridas de manera acrítica; igualmente es necesario superar el miedo al cambio que impide siempre el desarrollo de las capacidades propias por parte de alumnado y profesorado. Para el desarrollo práctico del modelo de programación creativa partimos de los objetivos específicos y de las capacidades creativas, y las relacionamos con el marco curricular y con las diversas estrategias creativas que el docente puede implementar en relación con el grupo-clase. Las posibles interacciones que pueden resultar se han contrastado en la práctica con un considerable éxito.

Aunque no es el objetivo de este trabajo desarrollar las bases teóricas del modelo, es importante recordar que parte de las capacidades que el alumno o la alumna ha de dominar en cada área del currículum, con el objetivo de estimular la creatividad. Estas capacidades se pueden proyectar en pensamientos, sentimientos y acciones, con el objetivo último de que el estudiante piense creativamente, sienta creativamente y actúe creativamente (Menchén, 1998:110). Como veremos en el siguiente apartado, el trabajo literario con títeres en perspectiva intercultural se nos revela como un espacio óptimo de intervención desde el punto de vista de la educación creativa. 


\section{DIVERSIDAD, LITERATURA Y TÍTERES}

Hemos visto hasta ahora algunos aspectos básicos de la educación intercultural y de sus objetivos, y la importancia de una acción educativa que respete y potencie la libertad y la creatividad de los discentes; asimismo hemos apuntado algunos elementos básicos a tener en cuenta para un trabajo de aula que tenga en cuenta la creatividad y la imaginación del alumnado. No hay ningún duda que la literatura puede ser un elemento de gran valor para conseguir estos objetivos, ya que es una fuente de conocimiento de otras culturas y de convivencia intercultural, además de tener un papel relevante en la adquisición y el desarrollo de las competencias básicas, sobre todo la competencia en comunicación lingüística, la competencia cultural y artística y la competencia social y ciudadana:

En última instancia, se trata, efectivamente, de formar ciudadanos en el sentido crítico del término, esto es, personas capaces de ejercer la ciudadanía de manera comprometida y responsable en la sociedad actual, así como contribuir decisivamente a la mejora de la convivencia y el respeto entre culturas (Ballester et al., 2010: 550).

El objetivo de la educación literaria es que el alumno adquiera lo que se denomina la competencia literaria (Ballester, 2007: 94), entendida como una capacidad humana que hace posible la producción y la recepción de la literatura. Se trata de una capacidad que no es innata y que está configurada por diversos factores entre los cuales la educación es uno de los más importantes. Por otro lado, la literatura es también fuente de conocimiento y actúa igualmente como transmisora de valores, normas y sistemas de una comunidad y de sus miembros: estas funciones, unidas a la de transmisión de la cultura, a la función liberadora y gratificadora, y a la del compromiso con la realidad, entre muchas otras, contribuyen a la formación integral de la persona. Tal como destaca el mismo autor, la literatura incluye tanto el saber como el saber hacer, el saber cómo se hace, el opinar y el sentir. Pero va mucho más allá: "No obstante, es mucho más, es una de las formas de humanizar al hombre y a la mujer. De dar sentido y configuración al caos que llevamos dentro y al que existe fuera" (Ballester, 2007: 100).

Antonio Mendoza insiste en la capacidad de la literatura, sobre todo en perspectiva comparada, de servir de enlace de aspectos culturales comunes y diversos (Mendoza, 1994: 17). La obra artística en general -y la literatura en particular-es un producto cultural de relaciones diversas y de conexiones de diferentes signos. $\mathrm{Ni}$ las civilizaciones ni las artes y la literatura evolucionan de manera aislada e incomunicada, sino mediante relaciones que fomentan el desarrollo de manera paralela, complementaria, por contraste, por influencia, por asimilación, por imitación, por rechazo, por transformación, por desintegración, etc. Un planteamiento de la enseñanza de la literatura acorde con la época actual y con el contexto multicultural 
debería tener en cuenta todos estos aspectos y también las conexiones culturales en la literatura: referencias, datos históricosociales e influencias metaliterarias:

Estamos convencidos de que el objetivo educativo de identificar y señalar conexiones y enlaces causales entre las producciones culturales habría de ser un objeto primordial para asegurar el respeto, la aceptación y la positiva valoración de otras culturas, puesto que en muchos casos la toma de conciencia del feedback cultural puede limar asperezas de apreciación y valoración (Mendoza, 1994: 13).

Mendoza considera por tanto que este enfoque comparatista de la enseñanza de la literatura tiene diversas ventajas: de esta apreciación de las interconexiones culturales hay que esperar el desarrollo en el alumnado de actitudes favorables y positivas hacia las producciones literarias correspondientes a otras lenguas y culturas; además, las propuestas elaboradas a partir de los procedimientos comparatistas pueden ser aplicables a todos los niveles de la enseñanza (y propone el uso en educación infantil de producciones relacionadas con la literatura oral, popular y folclórica), con el objetivo de alcanzar actitudes positivas hacia la diversidad.

Este potencial de la literatura en relación al hecho intercultural lo ponen de manifiesto también Ibarra y Ballester, para los cuales nos encontramos ante un poderoso instrumento de conocimiento de un mismo y del mundo, de descubrimiento de la otredad, de cohesión social y de creación de identidades plurales:

Nos encontramos en esencia ante el descubrimiento del otro, a partir del conocimiento de uno mismo y del mundo por medio del diálogo, en el que la literatura juega un papel primordial desde las primeras etapas vitales.

(...)

La configuración del lector, finalidad última de la educación literaria, constituye el germen de la ciudadanía activa y del sentimiento de pertenencia a través de la adquisición del código escrito y de la literatura como instrumento privilegiado desde su dimensión socializadora y cohesiva. La educación literaria desde la perspectiva intercultural permite leer el mundo y transformarnos paulatinamente en habitantes universales a medida que comprendemos la artificialidad de las fronteras geográficas o lingüísticas y la pertenencia a múltiples identidades (Ibarra y Ballester, 2010: 12).

Lo que afirmamos de la literatura en general y de sus posibilidades didácticas, estéticas y lúdicas, lo podemos resaltar de manera muy especial en el caso del teatro, y concretamente del teatro de títeres, que, por su naturaleza nos ofrece desde el primer momento la ocasión de reflexionar sobre la comprensión de las diferentes culturas, de la diversidad y de nuestras sociedades plurales.

Por lo que se refiere al teatro, Mendoza (2013) investiga a fondo el hecho de que en el teatro representado la recepción literaria la ejerce un espectador que no lee el texto sino que contempla un espectáculo, hecho que tiene como consecuencia toda 
una serie de particularidades que no están presentes de igual modo en la recepción del texto escrito: la implicación de un espectador competente requiere un buen número de conocimientos sobre las convenciones de este género. Además, la obra dramática necesita un proceso - desde el texto inicial- para llegar a la escena; en este proceso -que, como veremos, ofrece grandes posibilidades didácticas- intervienen diversos mediadores, no únicamente quienes actúan o dirigen la obra sino muchos otros eslabones imprescindibles en el proceso y que tienen que ver con las diversas profesiones del teatro.

El texto dramático es objeto de una serie de lecturas sucesivas por parte de los diferentes agentes implicados, y ese conjunto se fusiona de nuevo en la representación dramática (nueva, diferente e irrepetible en cada sesión) que se ofrece al espectador. A partir de aquí el espectador elabora su propia interpretación, no sólo del texto sino de todos los elementos (actuación, dirección, puesta en escena, vestuario...) que configuran el hecho teatral (Mendoza, 2013: 30). Como venimos diciendo, las posibilidades educativas de este proceso son innumerables, y seguir relegando a un segundo plano el aspecto del teatro como representación en los itinerarios de formación literaria -e intercultural- sería un grave error.

Juan Cervera ya alertaba en su momento del peligro de olvidar alguno de los dos aspectos centrales del teatro, que deberían estar presentes en todo proceso educativo: la iniciación en la literatura (dramática, en este caso) y la iniciación a la práctica del teatro (Cervera, 1998: 7). Así, conviene no olvidar que el texto teatral está escrito para ser representado, y que el trabajo relacionado con el teatro como representación ofrece unas posibilidades en la adquisición de la competencia literaria nada desdeñables desde el punto de vista del educador.

Dentro del mundo del teatro, el potencial del teatro de títeres en la educación ya fue puesto de relieve en los años 60 del pasado siglo por Mane Bernardo, a partir justamente de la universalidad de esta modalidad escénica. La especialista argentina fundamenta en esta presencia universal las posibilidades educativas y de conocimiento del niño en las diversas edades y en diferentes contextos. Un elemento tan arraigado en lo más profundo del ser humano ha de servir necesariamente para conocer mejor a las personas:

Toda cosa primitiva es imperecedera; arranca desde lo más profundo del instinto y retrotrae todas sus vivencias al mundo exterior. Datos psicológicos estos íntegramente aprovechables si están bien desarrollados y aplicados en los momentos y formas oportunas. De ello se desprende que en los diferentes tipos de la educación moderna el títere es un arma que ayuda eficazmente al buen conocimiento del niño en todas las edades, aspectos y condiciones (Bernardo, 1962: 13).

Este arraigo en lo más profundo del ser humano es el que -según Bernardo- está en la base del potencial educativo de los títeres, una capacidad apenas vislumbrada todavía hoy por los educadores. Por otro lado, una fuente adicional de posibili- 
dades educativas es el tratamiento multidisciplinar que pide el uso del títere, en una escuela que pide constantemente considerar la realidad como un todo y no fragmentada en diversas "materias de estudio" aisladas y sin ninguna relación entre sí: sobre todo en los primeros niveles educativos se abre paso la conciencia de la necesidad de un tratamiento -más allá de la teoría-integrador, globalizador y multidisciplinar.

Mane Bernardo profundiza en la defensa de las posibilidades de los títeres como herramienta educativa, critica algunos usos escolares del títere en la Argentina de mediados del siglo XX y alerta sobre la necesidad por parte de los docentes de recibir una formación adecuada para poder cumplir sus funciones educativas: la autora insiste en la paciencia y el espíritu pedagógico libre como ingredientes imprescindibles en la educación con títeres, junto con la valoración de las aportaciones que nacen de la creatividad del alumnado (Bernardo, 1962, 45). Igualmente, critica con vehemencia todo trabajo que se lleve a cabo desde el desconocimiento del títere como herramienta y del niño como elemento central del proceso educativo: tal desconocimiento, que nace de carencias formativas en cuanto a la técnica y del desprecio del niño como receptor y productor artístico, estaría en la base de la triste situación del títere en la escuela. La denuncia de la falta de formación por parte de los docentes será una constante a lo largo del tiempo y de los trabajos de diversos especialistas en la materia.

A partir de las reflexiones que hemos planteado hasta el momento, podemos establecer que teatro de títeres como vehículo de comunicación literaria ofrece una representación del mundo que corresponde a los valores de la sociedad que la produce, y una fuente de conocimiento de esta sociedad por parte de las otras; en definitiva, un punto de partida inmejorable para trabajar la otredad, la diversidad y la valoración positiva de las personas diferentes y de sus aportaciones, en un gran número de propuestas didácticas basadas en las diversas tradiciones del teatro de títeres en el mundo, y que abarcan todo el proceso de creación: investigación, documentación, organización, reparto de roles, ensayos, actuaciones, etc., adaptables a todos los niveles educativos y a las diferentes realidades escolares.

Las múltiples técnicas y maneras de entender el títere han entrado en contacto a lo largo de los siglos, y han configurado una compleja red, un tejido de influencias mutuas que ha enriquecido -y continúa haciéndolo- el panorama actual en todas partes. Por esta historia configurada a partir de las diversas tradiciones, que se influyen mutuamente y van creando nuevas formas, los títeres son un medio inmejorable para educar en la interculturalidad. Podríamos decir que, de alguna manera, los títeres simbolizan y resumen a la perfección las dinámicas de interacción de las diversas culturas y civilizaciones, un entretejido de relaciones siempre presentes en la historia de la humanidad y quizá acentuadas a lo largo del siglo XX y los inicios del XXI por toda una serie de circunstancias políticas, económicas y culturales. Esta simbolización es muy importante, tal como señala Henry Jurkowski al hablar del intercambio de referentes por parte de las diversas culturas y del enriquecimiento mutuo a través de los títeres. El autor polaco insiste en las posibilidades y las opor- 
tunidades que abre el conocimiento mutuo y el intercambio de cualquier tipo entre titiriteros de todo el mundo:

(...) Porque el intercambio de los valores espirituales, la relación con otras mitologías, religiones y filosofías, actualmente se efectúa también en el marco del teatro de títeres. Es de esperar, por tanto, que los titiriteros asiáticos, africanos y latinoamericanos no sean sólo sensibles al racionalismo y al pragmatismo europeos, sino que perciban asimismo el interés de la cultura europea por el destino común de la humanidad, y a la inversa: que los occidentales, siempre sensibles a las diferencias formales de las otras culturas, no se contentarán con recuperar las riquezas de las ornamentaciones, sino que reconocerán en las particularidades de pensamiento y de representación aquello que puedan tener de universal. (Jurkowski, 1993: 41).

El teatro de títeres nos ofrece la posibilidad de efectuar diversas actividades de aula con las que podemos trabajar contenidos, competencias y actitudes muy diversos, desde la investigación sobre tradiciones nacionales de títeres, folclore y literatura oral, tipos y formas de construcción y manipulación, escritura de guion, montaje escénico, dirección teatral, dinámica de grupo, organización del espectáculo, etc., siempre atendiendo a la edad y demás circunstancias del alumnado. Por otra parte, el incidir en los aspectos de la diversidad y la posibilidad de enriquecimiento mutuo que esta nos ofrece nos permitirá desarrollar actitudes positivas y avanzar en la adquisición de la competencia intercultural.

El punto de partida es la introducción del títere como un elemento que enriquece la dramatización y el teatro, y que al mismo tiempo hace accesible este último a alumnado que por su edad o por otras circunstancias encuentra dificultoso el acceso a la interpretación actoral. El otro aspecto importante es el desarrollo de la creatividad, para lo cual deberemos potenciar las actividades productivas y trabajar en muchos casos a partir de la improvisación dramática, para ir configurando la obra teatral final sin dejar de lado ninguna de las actividades que conforman el proceso creativo, siempre desde la perspectiva de la educación formativa y de la evaluación del proceso más que del producto final.

A la hora de establecer un punto de partida para el trabajo de la diversidad cultural mediante el títere, podemos llevar a cabo una investigación sobre las diversas tipologías de títeres, sobre sistemas de manipulación, sobre los personajes propios de las diversas tradiciones nacionales, sobre los nombres y las características de los personajes protagonistas en cada caso, etc. (Oltra Albiach, 2011), o bien partir de los textos (en muchos casos de tradición oral) que se representan en las diversas culturas, o incluso adaptar cuentos tradicionales del mundo a los diversos sistemas de manipulación de los títeres y ejercitar la creatividad también a través de la mezcla, la síntesis y el desarrollo de nuevos estilos, nuevas técnicas y nuevas historias que puedan representarse, bien ante un público, bien como trabajo de dramatización en el que los participantes son a la vez intérpretes y espectadores. 
Así pues, tal como hemos visto, en el mundo de los títeres se encuentran presentes de manera muy particular las dos fuerzas que operan en el terreno de la multiculturalidad: la tendencia al mestizaje, por una parte, y el esfuerzo por preservar las propias identidades culturales, de otra. El éxito o el fracaso de las tentativas de llevar a cabo una auténtica educación para la interculturalidad depende en gran parte de como solucionemos esta aparente paradoja. En cualquier caso, el teatro de títeres, con una experiencia milenaria en cuanto a intercambios y comunicación intercultural, tiene aún mucho que decir. Así lo han entendido un buen número de educadores que han visto en el títere una herramienta educativa en sus centros, que cada vez más acogen niños y niñas de diversas procedencias, ideologías, religiones y configuraciones familiares: el títere, con su enorme capacidad sugerente y su calidad de metáfora del ser humano, tiene un gran potencial didáctico en un contexto de intercambio permanente como el de hoy día, en el que hay que hacer un esfuerzo educativo para que el alumnado aprenda a valorar la diferencia y al diferente -en todos los sentidos posibles- como una fuente de humanización y enriquecimiento mutuo.

\section{CONCLUSIONES}

Hemos tratado de llevar a cabo un recorrido por las implicaciones educativas de la interculturalidad, y las posibilidades didácticas del teatro de títeres. A partir del trabajo de diversos autores en relación con la educación intercultural y el tratamiento de la diversidad en el aula, hemos llegado a algunas conclusiones básicas sobre cómo ha de desarrollarse tal proceso educativo. En segundo lugar, hemos realizado una aproximación al concepto de creatividad desde las propuestas de autores como Francisco Menchén (1998), y a su importancia en la escuela. Finalmente, hemos presentado la literatura y el teatro con títeres como una de las posibilidades para trabajar la interculturalidad y la diversidad en el aula desde un planteamiento flexible, abierto y creativo: la intercomunicación de técnicas y de formas teatrales a lo largo de la historia ha fundamentado una reflexión sobre la educación intercultural, sobre la diversidad y su tratamiento en la escuela, concebida no como espacio de homogeneización sino como ámbito de libertad, y sobre la utilización y las posibilidades de los títeres en un nuevo planteamiento educativo en favor de la igualdad desde el respeto a la diferencia, valorando todo aquello de nuevo, estimulante y enriquecedor que nos aporta.

\section{BIBLIOGRAFÍA}

AguAdo, María Teresa (2003): Pedagogía intercultural, Madrid, McGraw-Hill.

AlEgRE, Olga (2004): "Atienda la diversidad del alumnado universitario", en Programa para la mejora de la docencia universitaria, VILlAR ANGULO, L. M. (coord.), Madrid, Pearson-Prentice Hall, 97-121

BALLESTER, Josep (2007): L'educació literària, Valencia, Publicacions de la Universitat de València. 
N. IBARRA y A. DEvís (2010): "La educación literaria ante el reto de la interculturalidad", en Estudios sobre didácticas de las lenguas y sus literaturas, Herrera, J., Abril, M. y Perdomo, C. (coord.), Santa Cruz de Tenerife, Servicio de Publicaciones de la Universidad de La Laguna, 545-558.

BALLESTER, Josep y A. MAS (2003): "El component sociolingüístic en el desenvolupament de la competència comunicativa", en Llengua, societat $i$ ensenyament, vol. III, MARTINES, V. (coord.), Alicante, Institut Interuniversitari de Filologia Valenciana, 5-17.

BARTOLOMÉ PINA, Margarita (2008): "Un reto a la educación intercultural”, en Identidad y ciudadanía. Un reto a la educación intercultural, BARTOLOMÉ PINA, M. (ed.), Madrid, Narcea, 13-25.

BERNARDO, Mane (1962): Títeres y niños, Buenos Aires, Eudeba.

CERVERA, Juan (1998): Iniciación al teatro, Madrid, Bruño.

GARCÍA, Rafaela y A. SALES (2003): "Estratègies i tècniques per a la formació en actituds i valorsinterculturals", en Educació intercultural: la diversitat cultural a l'escola, SALES, A. (ed.), Castelló de la Plana, Publicacions de la Universitat Jaume I, 47-60.

IBARRA, Noelia y J. BALLESTER (2010): "La educación literaria e intercultural en la construcción de la ciudadanía", en Aula de Innovación Educativa, 197, 9-12.

JURKOWSKI, Henry (1993), "Vacas gordas y vacas flacas. Tendencias innovadoras y valores culturales", en Puck, 5, 37-41.

LLUCH, Xavier (2003), "Models i materials curriculars per a l'educació intercultural", en Educació intercultural: la diversitat cultural a l'escola, SALES, A. (ed.), Castelló de la Plana, Publicacions de la Universitat Jaume I, 25-34.

MARÍN, Miguel Ángel (2008): "La construcción de la identidad en la época de la mundialización y los nacionalismos", en Identidad y ciudadanía. Un reto a la educación intercultural, BARTOLOMÉ PINA, M. (ed.), Madrid, Narcea, 27-49.

MENCHÉn, Francisco (1998): Descubrir la creatividad, Madrid, Pirámide.

MENDOZA, Antonio (1994): Literatura comparada e intertextualidad, Madrid, La Muralla.

: (2013): "El receptor, espectador al teatre", en Articles de Didàctica de la Llengua i de la Literatura, 59, 27-37.

MínGUEZ, Xavier (2010), "Interculturalidad, multiculturalidad o localismo: un modelo para la LIJ catalana", en Estudios sobre didácticas de las lenguas y sus literaturas, HerrerA, J., ABrIL, M. y PERdomo, C. (coord.), Santa Cruz de Tenerife, Servicio de Publicaciones de la Universidad de La Laguna, 559-572.

Motos, Tomás y A. NAVARRO (2003): "El paper de la dramatització en el currículum", en Articles de Didàctica de la Llengua i la Literatura, 29,10-28.

OLLER, Carles y E. COLOMÉ (2010): Alumnado de otras culturas, Barcelona, Graó (col. Escuela Inclusiva 6). 
Oltra AlBIACH, Miquel A. (2011): "Les tradicions europees dels titelles: una proposta d'educació literària per a l'ensenyament primari", en Lenguaje y Textos, 34, 79-89.

PRAWER, Siegbert Salomon (1998): “QQué es la literatura comparada?”, en ROMERo LóPEZ, D. (ed.), Orientaciones en Literatura Comparada, Madrid, Arco/Libros, 21-36

SALES, Auxiliadora (2003): "L'organització i cultura escolar per a l'educació intercultural", en Educació intercultural: la diversitat cultural a l'escola, SALES, A. (ed), Castellón de la Plana, Publicacions de la Universitat Jaume I, 35-46. 